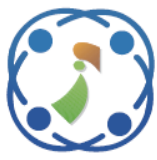

\title{
Estimation of the Quick Charging Station for Electric Vehicles based on Location and Population Density Data
}

\author{
Yuttana Kongjeen $^{1} \quad$ Wannawit Junlakan $^{1} \quad$ Krischonme Bhumkittipich $^{1 *}$ \\ Nadarajah Mithulananthan ${ }^{2}$ \\ ${ }^{1}$ Power and Energy System Research Center, Department of Electrical Engineering, Faculty of Engineering, \\ Rajamangala University of Technology Thanyaburi, Pathumthani, Thailand \\ ${ }^{2}$ School of Electrical Engineering and Information Technology, University of Queensland, Brisbane, Australia \\ *Corresponding author’s e-mail: krischonme.b@en.rmutt.ac.th
}

\begin{abstract}
This paper has presented the estimation methodology of the quick charging station for electric vehicles (EVs) based on both area and population density data. The proportion of EV owners per number of population in location data; is also used to compute the number of the quick charging stations. The population density data and proportion of EVs owners per number of population in area data are varied from 1 to $6 \%$ and 0.01 to $0.8 \%$, respectively. The simulation results showed that the number of EVs stations increased and the randomly selected Feeder No.1 was installed at EVs stations; of which range from No.1 to No.4. The total real power loss increased up to $18 \%$. Therefore, this study could be verified that the quick charging stations should be considered both optimal in sizing and location of EVs charging stations.
\end{abstract}

Keywords: Electric vehicles, Energy management system, Quick charging stations.

\section{Introduction}

The electric vehicles (EVs) have become an important issue in recent decades; mainly because of the tremendous impact of global warming. Many countries had promised and wanted to come to a solution; in terms of the reduction in carbon footprint emissions and renewable energy integration [1]. The reason for the energy consumption and being able to find new energy resources; have both been considered and applied to the electrical power system to be able to compensate energy from conventional sources. This issue is very important in order to use the energy management system (EMS); to be able to manage the total frame of the energy system which is called the smart grid system as shown in Fig. 1 [2].

According to the development of the EV and the charging station, many pieces of literature have been written to be able to study the effect of the large scale demand; in terms of the reduction of the steady state voltage stability, system losses, voltage profiles, voltage imbalance, and harmonics impact based on the EV charging model [3-10]. The impact of the EVs load had affected the electrical power system; in terms of power system stability. This impact needed to mitigate the transient frequency response of the electrical power system [5]. The voltage dependent load characteristic had found that the EV loads had caused the highest impact to the electrical power system when compared to conventional constant power load, constant current load, and constant impedance load in a single machine infinite bus [4]. The constant power modelling of the EVs load; without considering the voltage dependence of the ere also studied as shown in [6]. The EVs charging system couldn't provide the needed accuracy of information produced about the behaviour of the charging system during the charging process. Therefore, EV load has been developed based on the ZIP load that could be used to be able to analyse the behaviour of the EVs charger. 


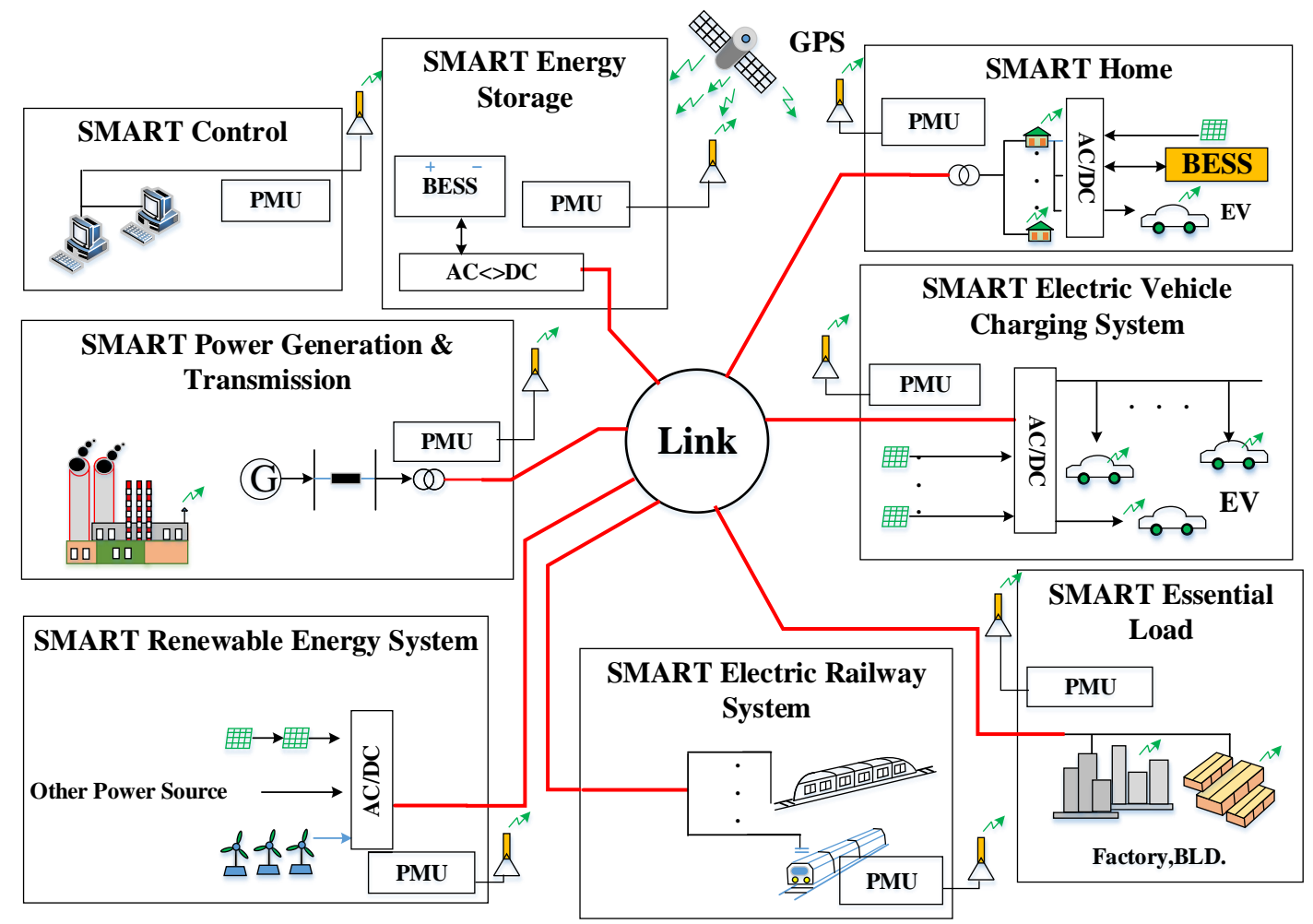

Figure. 1 Smart grid concept in the electrical power system

From the listed findings, the EVs load were integrated into the power grid and had determined the impacts of the EVs charging loads. A modelling of plug-in electric vehicles (PEVs) were studied; in order to identify the power flow analysis based on the voltage source converter (VSC). The PEVs active power of the instantaneous state of charge and discharge time expressed the exponential model as proposed in [7].

The vehicles to the grid (V2G) of the charging station could be significantly improved; when it comes to voltage stability on the power system while being able to use the battery energy storage. The battery packs of vehicles were introduced to the power grid; based on normal operating condition. The time variability of the nodal on the EV load, was evaluated by the queuing theory; with spatial varies arrival and service rate that can be moderated by sharing the EVs charging demand [8]. The heuristic algorithms were applied in the optimal charging scheduling of EVs in the smart grid by using thermal line limits, the load on the transformer, voltage limits, and parking availability patterns. The smart coordination of the EV demands had an improvement on the flexibility of the power system which had been studied. There could be a reduction; in terms of the cost of power system investment, and the reduction on aging of the power system element [9]. The multiobjective function based on Particle Swarm Optimization (PSO); was developed by using the
Monte Carlo simulation to generate the probability parameters. The daily load of the EVs were computed under behavioral conditions from the charging system. The modelling of EVs load were combined with spatial and temporal characteristics. Both characteristics are subdivided as follows: the load model under the autonomous charging mode, the load model under coordinated charging, and the discharging mode. The simulation results showed that the EVs had to coordinate both the charging and discharging modes; made operated economics better than s autonomous charging mode [10]. The objective of this paper is to define a methodology based on location and population density data for finding the number of quick charging station from estimation parameter. The number of quick charging station were used to investigate the impact of EVs load penetration on the electrical power system that to confirm the effected from EV load increase on the electrical power system should be managed.

The rest of the paper is arranged into sections as follows: Section 2 describes the type and charging levels of EVs. The modelling of EVs load for power system analysis and total real power loss are both presented in section 3 and section 4, respectively. Section 5 presents the methodology of estimate on the quick charging stations for the electric vehicle load based on population density factor. 


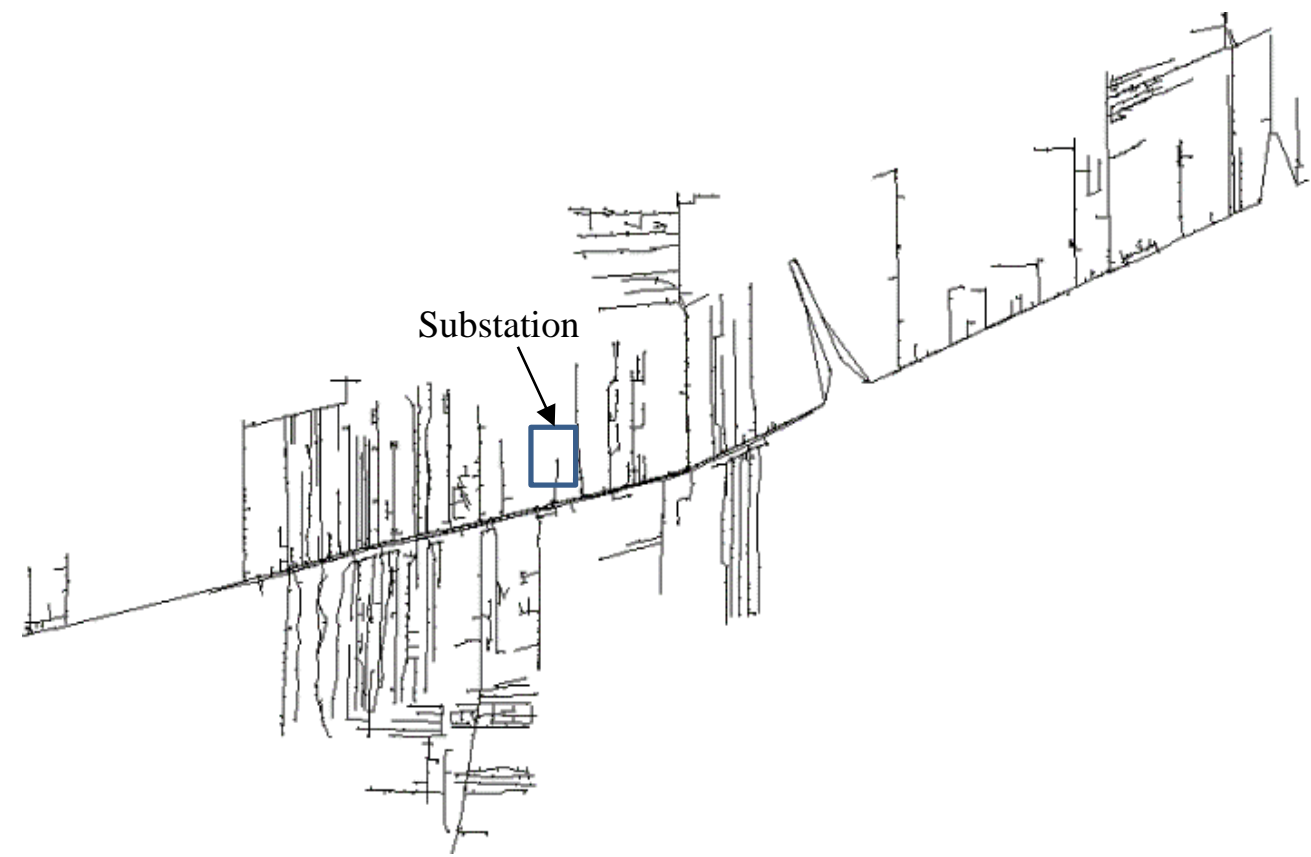

Figure. 2 Overall view of $22 \mathrm{kV}$ test system on GIS

The results on the six situations that were showered with various population density and various EVs owner's percentage were expressed in section. 6 . Finally, conclusion and discussion are given in section 7 .

\section{Quick charging station for electric vehicles load}

The fast charging EVs technology was developed for advancement of improved battery technology and power electronics control for an integrated drive system that a large amount of EVs will be able to be adopted into the electrical power system in near future. Energy consumption of EVs had different affects, based on the various models of EVs and charging level of the battery. In summary, the type and charging level of EVs were considered for energy supporting in an electrical power system; based on the fact EVs come in different makes, sizes, and weight.

\subsection{Type of electric vehicles}

Many types of EVs can be represented with the combination of engines and electric motors; which is also given the name of the pure electric motor type. This type of motor is able to be used in power conversion from the energy storage; which is found in EVs that have many types could be described in four types which are listed as the following below [11].

-Type I: Hybrid Electric Vehicles (HEVs) are powered by a main internal combustion engine with; an electric propulsion system to be able to transfer power to the traction drive by using the combination of an engine and an electric motor. The automatic control of power is defined by the torque of diving and velocity.

-Type II: Plugs-in Hybrid Electric Vehicles (PHEVs) are hybrid electric vehicles that were developed from HEVs; in addition to rechargeable batteries by plugging them into electrical outlets or through the charging stations. From this, there is a reduction in the consumption of fuel energy in the internal combustion engine. Therefore, the electricity is alternative energy source for of PHEVs and its selected first time in used.

-Type III: Battery Electric Vehicle (BEV) is a type of electric vehicle using chemical energy stored in rechargeable battery packs that consist of an electric motor, motor controller and battery to instead of internal combustion engine. They derive all power of movement from battery packs by charging the battery from charger at home or charging station.

-Type IV: Fuel Cell Electric Vehicle (FCEV) is a type of electric vehicle, which uses a fuel cell in place of a battery pack. The FCEV has the ability to generate electricity of power to the control drive system. Generally, the fuel cell uses oxygen from the air and compressed hydrogen; that are both important to the process that is derived from the fuel cell power production. However, the FCEV have been expensive and new technology that interest in the study and combine with the internal combustion engine. 
Table 1. SAE standard [9] for EVs charging

\begin{tabular}{lllll}
\hline Type of Charge & $\begin{array}{l}\text { Phase } \\
(\mathbf{1 P , 3 P})\end{array}$ & $\begin{array}{l}\text { Voltage } \\
\text { Level(V) }\end{array}$ & $\begin{array}{l}\text { Charging } \\
\text { Current(A) }\end{array}$ & $\begin{array}{l}\text { Power } \\
\text { Rated(kW) }\end{array}$ \\
\hline AC Level 1 & 1 & 120 & $12-16$ & $1.4-1.9$ \\
\hline AC Level 2 & 1 & 240 & $<80$ & $2.5-19.2$ \\
\hline AC Level 3 & 1,3 & 240 & $>80$ & $>20$ \\
\hline DC Level 1 & - & $200-450$ & 80 & 36 \\
\hline DC Level 2 & - & $200-450$ & 200 & 90 \\
\hline DC Level 3 & - & $200-600$ & 400 & 240 \\
\hline
\end{tabular}

Table 2. IEC61851-1 standard [11] for EVs charging

\begin{tabular}{lllll}
\hline Mode & $\begin{array}{c}\text { Specific } \\
\text { Connector } \\
\text { for EV }\end{array}$ & $\begin{array}{c}\text { Type of } \\
\text { Charging }\end{array}$ & $\begin{array}{c}\text { Charging } \\
\text { Current(A) }\end{array}$ & $\begin{array}{c}\text { Power } \\
\text { Rated(kW) }\end{array}$ \\
\hline 1 & No & AC slow charge & 16A per phase & $3.7-11$ \\
\hline 2 & No & AC slow charge & 32A per phase & $3.7-22$ \\
\hline 3 & Yes & $\begin{array}{l}\text { AC slow charge } \\
\text { or Semi quick } \\
\text { (1/3Phase) }\end{array}$ & $\begin{array}{l}\text { In accordance } \\
\text { with the } \\
\text { connector used }\end{array}$ & - \\
\hline 4 & Yes & DC charge & $\begin{array}{l}\text { In accordance } \\
\text { with the charger }\end{array}$ & - \\
& & &
\end{tabular}

This paper shows the effect of the quick charging station for EVs on a distribution network; which are possible for the EVs type to be considerate in energy consumption and in PHEVs and BEV as well, respectively.

\subsection{Charging level for electric vehicles}

The following factors that EVs consist of are as follows: distance ability; consist of battery sizing, velocity, user behavior, characteristics of the drive, weight and road traffic, respectively. To be able to have the charging time of EVs at the station relevant to level State of Charge (SOC), battery use and charging mode are selected in order to recharge at the charging station can, which could be referred as two standards could be described in Table 1, and Table 2, respectively.

In addition to select site for the quick charging station in terms of the optimal size of the EVs station, limits on the harmonics level into system; should be considered on a standard such as IEC-61000-3-4. The follow-up was watched closely in terms of the vicinity of the electrical organization standard; when connected to the electric power from Point of Common Coupling to the quick charging station.
Because of the harmonic interference to an electrical power system, the type of chargers were considered in terms of electrical power quality. However, when the charger connected into the electrical power system on single phase of charger type that may be effected in term voltage imbalance from the EVs penetration on the electrical power system. So that, should be managed in optimal condition for reducing the impact on the electrical power system.

\section{Modelling of electric vehicle load}

The power consumption of the EV, was derived from the charging characteristics that consists of the $\mathrm{AC}$ to $\mathrm{DC}$ converter; by being able to convert energy from the grid or the quick charging station sufficiently to the energy storage in battery packs; which are called the grid to vehicle $(\mathrm{G} 2 \mathrm{~V})$. A polynomial load (ZIP) is a one type of voltage dependency load that is represented in the composite load characteristic from variance voltage on charging process and power system network. Therefore, the polynomial equation for active power and reactive power are shown in Eq. (1), and Eq. (2), respectively [6], [12]. 


$$
\begin{aligned}
& P_{i}=P_{0}\left(a P \cdot\left(\frac{v}{v_{0}}\right)^{e_{-} a P}+b P \cdot\left(\frac{v}{v_{0}}\right)^{e-\mathrm{b} P}\right. \\
& \left.+(1-a P-b P) \cdot\left(\frac{v}{v_{0}}\right)^{e_{-} \mathrm{c} P}\right) \\
& Q_{i}=Q_{0}\left(a Q \cdot\left(\frac{v}{v_{0}}\right)^{e_{-} a P}+b Q \cdot\left(\frac{v}{v_{0}}\right)^{e-b P}\right. \\
& +(1-a Q-b Q) \cdot\left(\frac{v}{v_{0}}\right)^{e-c} P
\end{aligned}
$$

Where $1-a P-b P=c P, 1-a Q-b Q=c Q$

0 is the subscribe indices of the initial state or operating condition.

$v$ is the bus voltage magnitude.

$e_{-} x X$ is the exponents of parameter; which are equal to 0,1 , and 2 that that are represented by constant power, constant current, and constant impedance, respectively.

$a P, b P, c P, a Q, b Q, c Q$ are the parameters of the model; and are the coefficients that were computed [6] from computer simulations of a typical charging system.

\section{Total real power loss}

The total real loss level of the power system can be solved and improved by the transfer of power to the load. The real power loss is computed by using Eq. (3), to be able to calculate the loss level. The electrical power system has a significant impact on the optimal cost of the power system as shown [13].

$$
\mid \text { Real power } \mid=\sum_{i=1}^{N} I_{i}^{2} \cdot R_{i}
$$

where $N$ is the number of lines in a distributed power system, $I$ is the current flow of transmission line and $R$ is the resistance value of the line.

\section{Estimation of the quick charging station}

The number of quick charging stations are important, in order to be able to prepare the energy sources to support the electrical power system. The estimation factor is relevant of charging time, and the number of EV car owners; per the number of population in the area. The mobility pattern of EVs were assumed that each EVs attended to the charging station in close to linear on 24 hour and sizing of batteries capacity for charging were assumed that each EVs same battery capacity. As the SOCs were assumed that each EVs same level of SOCs. Meanwhile, the deviation on the parameter can be shown as follows.

\subsection{Charging time of EV load on the quick charging station}

Time of charge on the battery in EVs load on the quick charging station, is relevant to amount of energy demand of an electrical power system. The SOC and the sizing of battery packs are both considered; in terms of the rated power on the power charger in EVs. In summary, charging time which is written $t_{E V}$ as, can be estimated as Eq. (4), [14].

$$
t_{E V}=\frac{k W h_{E V} \times\left(S O C^{F}-S O C^{T h}\right)}{P_{C H} \times e f f_{C H}}
$$

where $t_{E V}$ is charging time of each $\mathrm{EV}\left(\mathrm{Hr}\right.$.), $k W h_{E V}$ is the battery capacity of the $\mathrm{EV}(\mathrm{kWh}), S O C^{F}$ is the final state of charge on the EV (\%), $S O C^{T h}$ is the threshold state of charge on the EV $(\%), P_{C H}$ is the rated power output of the DC fast charger $(\mathrm{kW})$, and eff $f_{C H}$ is the efficiency of fast charging station or charger.

\subsection{Number of quick charging stations}

The number of quick charging stations were rerated in many parameter to consider the computation; which are based on the estimates to be able to find the value which can be shown as Eq. (5), following [15].

$$
n f \text { station } \geq \frac{A \times \text { pdensity } \times p B E V}{s h \times n c p \times n s t}
$$

where $A$ is the size of an area (sq. $\left.\mathrm{km}^{2}\right)$, pdensity is the population density $\left(\mathrm{man} / \mathrm{km}^{2}\right), p B E V$ is the proportion of the EV owners per the number of population in an area, $n c p$ is the number of charging sockets in a charging station, $n s t$ is the number of services per hour of the charging station per hour of charging time in EVs are equal to $n s t=\frac{1 h r}{t_{E V}}$ and $s h$ is the number of services per hour of the charging station in a day. 


\subsection{The proportion of car owners per the number of population in an area}

The car owners per the number of population in an area are used to be able to find the most accurate estimate on the number of EV car owners in an area and are considered. These estimates were rerated in Eq. (6), and the gross domestic product per population could be computed as Eq. (6) [11].

$$
\operatorname{In}\left(\frac{V O}{0.812-V O}\right)=1.3558 \operatorname{In}(\text { GDPpCap })-18.1253
$$

where $V O$ is the amount of vehicle owners per population in an area GDPpCap ; is the gross domestic product per population.

However, in a realistic situation the EV owners have many factors to consider which are written as follows: to estimate because of limitation on income, amount of quick charging stations, and government policy, respectively. Consequently, this paper supposes the EVs owned are $0.1 \%$ of vehicle owners that possibly and nearly match the number of EVs and the population growth of about $0.6 \%$ [16].

\section{Simulation results}

The configuration of the radial distribution system area is the case study area; which is selected to simulate the amount of quick charging stations as shown in Fig. 3, The numbers of quick charging stations were considered on two constraints that consisted of: varying population density between 1$6 \%$, and varied EV owners per population between $0.01 \%-0.8 \%$, respectively.

The population growth trend has been affected by the amount of quick charging stations and energy consumption on the electrical power system. This paper has outlined the use of feeder No.1 (FD1) on the test system to randomize positions on the quick charging stations; by the total size of the charger of approximately $2,000 \mathrm{~kW}$, power factor 0.9 , and step down transformer rated at $22 \mathrm{kV} / 400 \mathrm{~V}, 2,500 \mathrm{kVA}$, respectively. Therefore, the charging stations were assumed at the rated of step down transformer and used for computing the total real power loss of the electrical power system on balance load condition. As the time for charging were assumed on 24 hours.

The simulation results showed total real power loss of the test system in each case of test conditions. Therefore, the parameters related could be shown in Table 3,. The parameter of the quick charging station from Table 1, is used to compute the sizing; in order to consider population density the charger parameter and charging time. The results showed the amount of

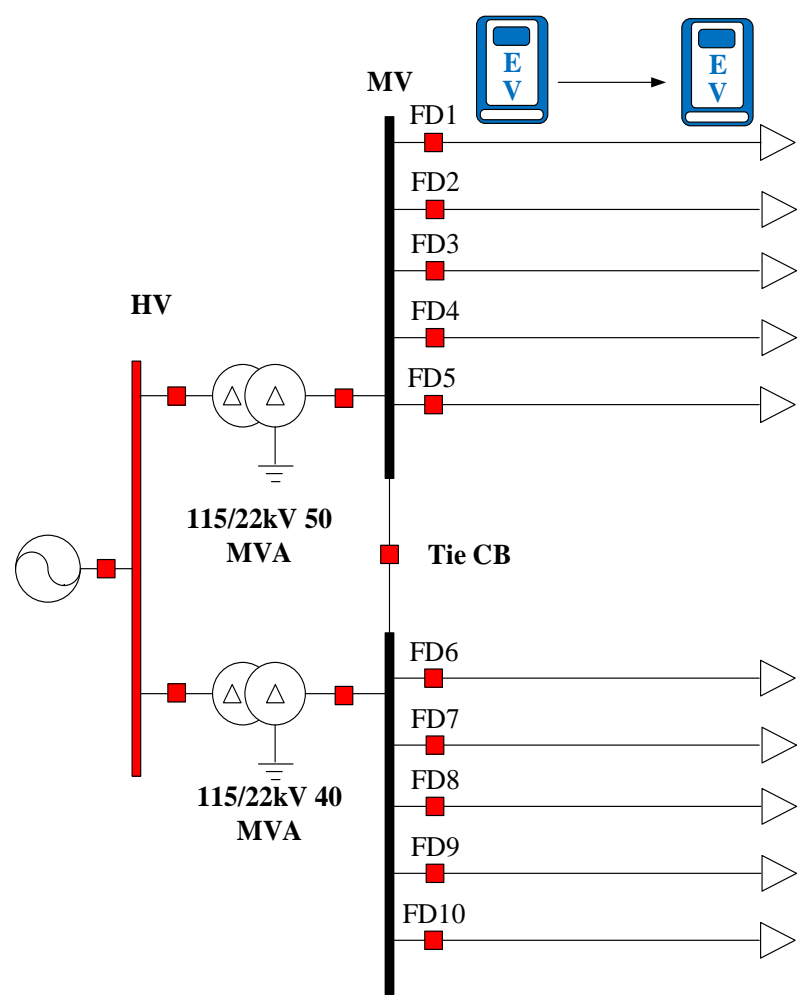

Figure. 3 Single line diagram of the test system with a total rate of 90MVA

Table 3. Parameter to estimate the quick charging station

\begin{tabular}{ll}
\hline Variables & Parameter \\
\hline$k W h_{E V}$ & 40 \\
\hline$S O C^{F}$ & 80 \\
\hline$S O C^{T h}$ & 30 \\
\hline$P_{C H}$ & 250 \\
\hline$e f f_{C H}$ & 0.95 \\
\hline$t_{E V}$ & 0.08421 \\
\hline$A$ & 112.124 \\
\hline Population & 190,163 \\
\hline$p d e n s i t y$ & $1,696.01$ \\
\hline$s h$ & 24 \\
\hline$V O$ & 138,535 \\
\hline$p P E V(V O \times 0.1 \%)$ & 138.54 \\
\hline$n c p$ & 8 \\
\hline$n s t$ & 12 \\
\hline Transformer size $(\mathrm{kVA})$ & 2,500 \\
$(n c p \times 250 \mathrm{k} W \times 125 \%)$ & \\
\hline
\end{tabular}

services calculated each day, and the amount of time on a consistent connection to the grid though the step down transformer at $125 \%$ of safety factor. These variables are represented in terms of the size of the quick charging station to be able to compute real power loss in this paper. The test system from GIS was used to solve from the purpose of this paper 
which the number of estimation of the quick charging station based on location and population density data. Those quick charging are provided and prepare a guide line for supporting the energy sources of the electric power system

The simulation results from Table 4, showed the number of the quick charging station from estimate equal a station when define population density of $1 \%$ and varies $\% \mathrm{EV}$ owner from $0.01 \%$ to $0.8 \%$. Therefore, the $\%$ of population density were a little relate to the $\% \mathrm{EV}$ owner.

The simulation results from Table 5, showed the number of quick charging stations, from an estimate equal to 1 and 2 stations with a defined population density of $2 \%$ and various $\% \mathrm{EV}$ owners from $0.01 \%$ to $0.8 \%$. From the above measurements, the $\%$ of population density that were related to the $\% \mathrm{EV}$ owners and growth; showed that they were both the same direction to the population density.

The simulation results from Table 6 , showed the number of quick charging stations from an estimate equal to 1,2 and 3 stations with a defined population density of $3 \%$ and various $\% \mathrm{EV}$ owners from $0.01 \%$ to $0.8 \%$. Consequently, the $\% \mathrm{EV}$ owners were directed affected by the number of quick charging stations and this showed in the results recorded. However, the population density has been imported and needed in order to consider the conditions.

The simulation results from Table 7, showed the number of quick charging stations from an estimate equal to $1,2,3$ and 4 stations; with a defined population density of $4 \%$ and various $\% \mathrm{EV}$ owners. Meanwhile, the population density, \% EV owners were directly affected, and were key to variance on the number of quick charging stations.

The simulation results from Table 8 , showed the number of quick charging stations from an estimate equal to 1, 2, 3, 4 and 5 stations; that confirmed the results from an estimate on the value of population density and $\% \mathrm{EV}$ owners that were affected.

The simulation results from Table 4, to Table 9, showed that the amount of quick charging stations had an estimate of varying measurements on population density between $1 \%-6 \%$, and EV owners were between $0.01 \%-0.8 \%$. The affected integer value from the number of quick charging stations, consisted of data from population density and EV owners. In addition to the amount EV owners, the parameters are very important in order to calculate an accurate reading; based on the number of quick charging stations. Furthermore, the EV owner value is a major factor in terms of determine the amount of penetration level on the EVs load in an electrical
Table 4. Estimate quick charging station results

\begin{tabular}{llllll}
\hline Vary pdensity & \multicolumn{7}{c}{$1 \%$} \\
\hline Vary EV owner & 0.01 & 0.05 & 0.10 & 0.20 & 0.30 \\
\hline nfStation & 0.01 & 0.05 & 0.11 & 0.22 & 0.34 \\
\hline Round up & 1 & 1 & 1 & 1 & 1 \\
\hline Vary EV owner & 0.40 & 0.50 & 0.60 & 0.70 & 0.80 \\
\hline nfStation & 0.45 & 0.57 & 0.68 & 0.8 & 0.91 \\
\hline Round up & 1 & 1 & 1 & 1 & 1 \\
\hline
\end{tabular}

Table 5. Estimate quick charging station results

\begin{tabular}{clllll}
\hline Vary pdensity & \multicolumn{5}{c}{$2 \%$} \\
\hline Vary EV owner & 0.01 & 0.05 & 0.10 & 0.20 & 0.30 \\
\hline nfStation & 0.02 & 0.11 & 0.22 & 0.45 & 0.68 \\
\hline Round up & 1 & 1 & 1 & 1 & 1 \\
\hline Vary EV owner & 0.40 & 0.50 & 0.60 & 0.70 & 0.80 \\
\hline nfStation & 0.91 & 1.14 & 1.37 & 1.60 & 1.82 \\
\hline Round up & 1 & 2 & 2 & 2 & 2 \\
\hline
\end{tabular}

Table 6. Estimate quick charging station results

\begin{tabular}{llllll}
\hline Vary pdensity & \multicolumn{5}{c}{$3 \%$} \\
\hline Vary EV owner & 0.01 & 0.05 & 0.10 & 0.20 & 0.30 \\
\hline nfStation & 0.03 & 0.17 & 0.34 & 0.68 & 1.02 \\
\hline Round up & 1 & 1 & 1 & 1 & 2 \\
\hline Vary EV owner & 0.40 & 0.50 & 0.60 & 0.70 & 0.80 \\
\hline nfStation & 1.37 & 1.71 & 2.05 & 2.40 & 2.74 \\
\hline Round up & 2 & 2 & 3 & 3 & 3 \\
\hline
\end{tabular}

Table 7. Estimate quick charging station results

\begin{tabular}{llllll}
\hline Vary pdensity & \multicolumn{7}{c}{$4 \%$} \\
\hline Vary EV owner & 0.01 & 0.05 & 0.10 & 0.20 & 0.30 \\
\hline nfStation & 0.04 & 0.22 & 0.45 & 0.91 & 1.37 \\
\hline Round up & 1 & 1 & 1 & 1 & 2 \\
\hline Vary EV owner & 0.40 & 0.50 & 0.60 & 0.70 & 0.80 \\
\hline nfStation & 1.82 & 2.28 & 2.74 & 3.20 & 3.65 \\
\hline Round up & 2 & 3 & 3 & 4 & 4 \\
\hline
\end{tabular}

Table 8. Estimate on the quick charging station results

\begin{tabular}{llllll}
\hline Vary pdensity & \multicolumn{5}{c}{$5 \%$} \\
\hline Vary EV owner & 0.01 & 0.05 & 0.10 & 0.20 & 0.30 \\
\hline nfStation & 0.05 & 0.28 & 0.57 & 1.14 & 1.71 \\
\hline Round up & 1 & 1 & 1 & 2 & 2 \\
\hline Vary EV owner & 0.40 & 0.50 & 0.60 & 0.70 & 0.80 \\
\hline nfStation & 2.28 & 2.85 & 3.43 & 4.00 & 4.57 \\
\hline Round up & 3 & 3 & 4 & 5 & 5 \\
\hline
\end{tabular}

power system. Consequently, the number of quick charging stations had an estimate that could be used to represent EVs load on the electrical power system; in order to evaluate the impact on EVs load for future planning. 
Table 9. Estimate on quick charging stations results

\begin{tabular}{llllll}
\hline Vary pdensity & \multicolumn{5}{c}{$6 \%$} \\
\hline Vary EV owner & 0.01 & 0.05 & 0.10 & 0.20 & 0.30 \\
\hline nfStation & 0.06 & 0.34 & 0.68 & 1.37 & 2.05 \\
\hline Round up & 1 & 1 & 1 & 2 & 3 \\
\hline Vary EV owner & 0.40 & 0.50 & 0.60 & 0.70 & 0.80 \\
\hline nfStation & 2.74 & 3.43 & 4.11 & 4.80 & 5.48 \\
\hline Round up & 3 & 4 & 5 & 5 & 6 \\
\hline
\end{tabular}

Table 10. Total real power results

\begin{tabular}{llllll}
\hline & \multirow{2}{*}{ Base } & \multicolumn{4}{c}{ Station } \\
\cline { 3 - 6 } & & 1 & 2 & 3 & 4 \\
\hline Node No. & 27571 & 27548 & 27556 & 52674 \\
\hline $\begin{array}{l}\text { Power } \\
\text { Loss(MW) }\end{array}$ & 3.00 & 3.04 & 3.42 & 3.52 & 3.54 \\
\hline $\begin{array}{l}\text { Compare } \\
\begin{array}{l}\text { Base Case } \\
(\%)\end{array}\end{array}$ & 0 & 1.30 & 13.84 & 17.30 & $\begin{array}{l}18.0 \\
\%\end{array}$ \\
$\%$
\end{tabular}

The simulation results from Table 10, showed that the power loss level was increased, after it was installed in a randomized position in the quick charging stations; from 1 station to 4 stations at a rate of $2,500 \mathrm{kVA}$ per station. The real power loss level showed an increase of $1.3 \%, 13.84 \%, 17.30 \%$, and $18 \%$; when compared to the base case for quick charging of 1 station to 4 stations, respectively. Therefore, the optimal size and position needed to consider were based on; finding the low level of power loss and improvement of static voltage stability on the electrical power system.

\section{Conclusion}

In this paper, relevant information was used to collect: area data, population density data, and proportion of EV owners per the number of population in the test system area; for solving the number of quick charging stations on the EVs load. The simulation results showed the effect of estimation on the population density between $1 \%$ $6 \%$ and EV car owners between $0.01 \%-0.8 \%$; that showed an increase in the amount of quick charging stations which gathered in size from 1 station to 6 stations. However, when randomized for installation quick charging stations on feeder FD1 in 1 station to 4 stations; that simulation results had shown that the real power loss on the electrical power system were increased from $3.00 \mathrm{MW}$ to $3.54 \mathrm{MW}$ with a remainder of approximately $18 \%$. Therefore, the optimal quick charging stations must be considered for reduction of effect on the electrical power system.
In the future, we will be studying the optimization problem of quick charging stations and analysis on the impact from quick charging stations.

\section{Acknowledgments}

The Authors would like to thank the Provincial Electricity Anthology of Thailand (PEA) for data and research supported.

\section{References}

[1] R. Sioshansi and P. Denholm, "Emissions Impacts and Benefits of Plug-in Hybrid Electric Vehicles and Vehicle to Grid Services", National Renewable Energy Laboratory, Vol.43, pp. 1199-1204, 2009.

[2] Y. Kongjeen and K. Bhumkittipich, "Modeling of Electric Vehicle Loads for Power Flow Analysis based on PSAT ", In: Proc. of the 13th International Conference on Electrical Engineering /Electronics, Computer, Telecommunications and Information Technology (ECTI-CON), pp. 1-6, 2016.

[3] J. Y. Yong, V. K. Ramachandaramurthy, K. M.Tan, and N. Mithulananthan, "Review on the state-of-the-art technologies of electric vehicle its impacts and prospects", Renewable and Sustainable Energy Reviews, Vol. 49, pp.365385, 2015.

[4] C.H. Dharamakeerthi, N. Mithulananthan, and T.K. Saha, "Impact of electric vehicle fast charging on power system voltage stability", International Journal of Electrical Power and Power Energy System, Vol. 57, pp. 241-249, 2014.

[5] H. W. Qazi, D. Flynn, and Z.H. Rather, "Impact of Electric Vehicle Load Response Variation on Frequency Stability", In: Proc. of the 2016 IEEE PES Innovative Smart Grid Technologies Conference Europe, pp. 1-6, 2016.

[6] A. Haidar and K. M. Muttaqi, "Behavioral characterization of electric vehicle charging loads in a distribution power grid through modeling of battery chargers", IEEE Transactions on Industry Application, Vol. 52, pp. 483-492, 2016.

[7] A. Jimenez and N. Garcia, "Power Flow Modeling and Analysis of Voltage Source Converter-Based Plug-in Electric Vehicles", In: Proc. of Power and Energy Society General Meeting, pp.1-6, 2011.

[8] D. Tang, P. Wang, and Q. Wu, "Probabilistic modelling of nodal electric vehicle load due to fast charging stations", In: Proc. of the 2016 International Conference on Probabilistic 
Methods Applied to Power Systems, pp. 1-6 , 2016.

[9] M. Alonso, H. Amaris, J. G. Germain, and J. M. Galan, "Optimal Charging Scheduling of Electric Vehicles in Smart Grids by Heuristic Algorithms", Energies, Vol.7, pp.2449-2475, 2014.

[10] H. Liu, H. Zhuangm and H. Wu, "MultiObjective Dynamic Economic Dispatch of Migrogrid System Including Vehicle-to-Grid", Energies, Vol.8, pp.4476-4495, 2015.

[11] Y. Laoonual, "Assessment of Electric Vehicle Technology Development and Its Implication in Thailand", National Science and Technology Development Agency, Vol.2, pp.135-137, 2015.

[12] P. Kundur, Power System Stability and Control, McGraw-Hill: New York, pp. 272-273, 1994.

[13] P. Sindhu Priya and N. Chaitanya Kumar Ready, "Optimal Placement of the DG in Radial
Distribution System to Improve the Voltage Profile", International Journal of Science and Research, Vol. 4, pp. 2310-2315, 2015.

[14] N. Leeprechanon, P. Phonrattanasak, and M. K. Sharma, "Optimal Planning of Public Fast Charging Station on Residential Power Distribution System", In: Proc. of the International Transportation Electrification Conference \& Expo, pp.1-6, 2016.

[15] P. Phonrattanasak and N. Leeprechanon, "Development of Fast Charging Station for Thailand", International Journal of Innovation, Management and Technology, Vol.3, pp. 668674, 2012.

[16] P. Vapattanawong and P. Prasartkul, "The future of population of Thailand", Institute for Population and Social Research, Mahidol University. 